OPEN ACCESS

Edited by:

Jian Zhang,

Southern Medical University, China

Reviewed by:

Adeleye Oluwatosin Adeshakin, St. Jude Children's Research Hospital, United States

Michael Alexander Morgan, Hannover Medical School, Germany Michael Brown,

Royal Adelaide Hospital, Australia

${ }^{*}$ Correspondence: Joe Jiang Zhu joe.zhu@petermac.org

${ }^{\dagger}$ These authors share first authorship

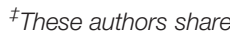
senior authorship

Specialty section: This article was submitted to Cancer Immunity and Immunotherapy, a section of the journal Frontiers in Immunology

Received: 12 November 2021 Accepted: 22 December 2021 Published: 12 January 2022

Citation:

Qin VM, Haynes NM, D'Souza C, Neeson PJ and Zhu JJ (2022) CAR-T Plus Radiotherapy: A Promising Combination for Immunosuppressive Tumors.

Front. Immunol. 12:813832. doi: 10.3389/fimmu.2021.813832

\section{CAR-T Plus Radiotherapy: A Promising Combination for Immunosuppressive Tumors}

\author{
Vicky Mengfei Qin ${ }^{1,2 t}$, Nicole M. Haynes ${ }^{3,4 t}$, Criselle D'Souza ${ }^{1,4}$, Paul J. Neeson ${ }^{1,4 \ddagger}$ \\ and Joe Jiang Zhu ${ }^{1,4 *}$ \\ ${ }^{1}$ Cancer Immunology Program, Peter MacCallum Cancer Centre, Melbourne, VIC, Australia, ${ }^{2}$ Department of Clinical \\ Pathology, Faculty of Medicine, Dentistry and Health Sciences, University of Melbourne, Melbourne, VIC, Australia, \\ ${ }^{3}$ Division of Cancer Research, Peter MacCallum Cancer Centre, Melbourne, VIC, Australia, ${ }^{4}$ Sir Peter MacCallum Department of \\ Oncology, Faculty of Medicine, Dentistry and Health Sciences, University of Melbourne, Melboume, VIC, Australia
}

Radiotherapy $(\mathrm{RT})$ is the standard-of-care treatment for more than half of cancer patients with localized tumors and is also used as palliative care to facilitate symptom relief in metastatic cancers. In addition, RT can alter the immunosuppressive tumor microenvironment (TME) of solid tumors to augment the anti-tumor immune response of immune checkpoint blockade (ICB). The rationale of this combination therapy can also be extended to other forms of immunotherapy, such as chimeric antigen receptor $\mathrm{T}$ cell (CAR-T) therapy. Similar to ICB, the efficacy of CAR-T therapy is also significantly impacted by the immunosuppressive TME, leading to compromised T cell function and/ or insufficient T cell infiltration. In this review, we will discuss some of the key barriers to the activity of CAR-T cells in the immunosuppressive TME and focus on how RT can be used to eliminate or bypass these barriers. We will present the challenges to achieving success with this therapeutic partnership. Looking forward, we will also provide strategies currently being investigated to ensure the success of this combination strategy in the clinic.

\footnotetext{
Keywords: radiotherapy (RT), chimeric antigen receptor T cell (CAR-T), solid tumor, immunosuppression, tumor microenvironment (TME)
}

\section{INTRODUCTION}

Adoptive cell transfer (ACT) has shifted the therapeutic paradigm for cancer patients in recent years. Transducing $\mathrm{T}$ cells with a chimeric antigen receptor (CAR) to redirect their antigen specificity against a defined tumor antigen has further broadened the use of ACT. CAR-T cells can recognize tumor-associated surface antigens via the single-chain variable fragment $(\mathrm{scFv})$ and initiate anti-tumor immune responses by intracellular signaling domains, such as $\mathrm{CD} 3 \zeta$ and $\mathrm{CD} 28$ (1). CAR-T therapy has demonstrated remarkable anti-cancer activity, achieving long-term remission in patients with refractory B cell malignancies (2). However, similar success with CAR-T cell therapy has not been achieved in solid tumors (3).

Solid tumors can be characterized into two distinct subsets based on the inflammatory status of the TME (4). Tumors (eg. melanoma) with a high inflammation signature tend to respond well to ICB (5), an effect largely mediated by $\mathrm{CD}^{+}$effector T cells $(6,7)$; however, the development of resistance to immunotherapy is common. The presence of liver metastases is also being increasingly 
recognized as a barrier to ICB efficacy, even in the context of melanoma $(8,9)$. Tumors that support an immune excluded or deserted TMEs, such as prostate and pancreatic cancers, are described as immunosuppressive $(10,11)$, and typically fail to respond to ICB and CAR-T therapy. These immunosuppressive tumors lack T-cell chemokines to drive the recruitment of $\mathrm{CD}^{+}$ effector $\mathrm{T}$ cells or CAR-T cells and are also enriched with suppressor cells that compromise $\mathrm{T}$ cell persistence and function. To overcome these immunosuppressive features, the value of TME-altering therapies, such as RT, is actively being explored.

RT is the standard-of-care treatment used for curative or palliative intent in close to $50 \%$ of cancer patients (12). Factors including total dose, fractionation scheme, hypoxia, and the intrinsic radiosensitivity of tumor cells all come into play in influencing the overall impact of RT on the TME (13-15) and its ability to reactivate host anti-tumor immune responses (16). Evidence to support the rationale for combining CAR-T cells with radiation therapy is growing. The RT effect on the TME, and the mechanisms whereby this occurs, have been widely studied in a variety of tumor models using different dose/ fractionation schemes (Table 1). As a TME-modifying therapy, RT can induce the release of chemokines, such as CXCL9, to augment $\mathrm{T}$ cell trafficking (Figure 1 (1)/(2), increase the expression of adhesion molecules that may promote $\mathrm{T}$ cell infiltration (Figure 1 (3/(4)), alter the immune cell composition in the TME (Figure 1 (5/6), and increase the expression of immune-stimulatory cytokines to enhance the functional activity of effector T cells in the TME (Figure 1 8/9) (32). By changing the TME and creating a niche for immune cells, these benefits may synergize with immunotherapies, including CAR-T therapy.

In the clinic, patients with immunosuppressive tumors have few therapeutic options, have high morbidity, poor long-term survival, and comprise an urgent unmet clinical need. In this review, we will focus on the potential benefits and challenges for combining RT with CAR-T cells for the treatment of immunosuppressive tumors and provide insights into how to manipulate these two treatments to maximize clinical benefit.

\section{CURRENT CHALLENGES FOR CAR-T CELLS THAT CAN BE TARGETED BY RT}

Poor trafficking, tumor penetration, and persistence of CAR-T cells, as well as tumor antigen heterogeneity and immunosuppression, are all major barriers to the success of CAR-T therapy in solid tumors. In this section, we will outline some of the mechanisms by which RT can overcome such challenges.

\section{Insufficient Recruitment of CAR-T Cells}

Efficient trafficking of CAR-T cells to solid tumors within peripheral tissue has proven to be a significant challenge. The tumor stroma comprises immunosuppressive cells, cancer-associated fibroblasts

TABLE 1 | Evidence of the potential synergistic effect of RT in combination with CAR-T cells.

\begin{tabular}{|c|c|c|c|}
\hline Tumor model & Scheme & Mechanism & Reference \\
\hline \multicolumn{4}{|c|}{ Preclinical evidence of RT as a TME altering therapy } \\
\hline Melanoma & $1 \times 15 G y$ & RT-induced type I IFN promoted CXCL10 expression, leading to increased CD8 ${ }^{+} \mathrm{T}$ cell infiltration. & Lim et al (17), \\
\hline Multiple models & $3 \times 8 G y$ & RT activated the STING pathway and induced type I IFNs to recruit DC and CD8 ${ }^{+} T$ cells. & $\begin{array}{l}\text { Vanpouille-Box et. } \\
\text { al (18), }\end{array}$ \\
\hline Prostate cancer & $10 \times 2 G y$ & RT remodeled the tumor vasculature and improved oxygenation. & Potiron et al. (19), \\
\hline $\begin{array}{l}\text { Non-small cell lung } \\
\text { carcinoma }\end{array}$ & $\begin{array}{l}1 \times 18 G y \text { and } 3 \times \\
6 G y\end{array}$ & $\begin{array}{l}\text { Irradiated CAF decreased the pro-tumorigenic potential that affected angiogenesis and tumor } \\
\text { growth. }\end{array}$ & Grinde et al. (20), \\
\hline Breast cancer & $3 \times 8 G y$ & $\begin{array}{l}\mathrm{RT} \text { induced up-regulation of ICAM- } 1 \text { to enhance both the activation and tumor infiltration of } \mathrm{CD} 8^{+} \mathrm{T} \\
\text { cells. }\end{array}$ & Zhao et al. (21), \\
\hline Melanoma & $1 \times 15 \mathrm{~Gy}$ & $\begin{array}{l}\text { RT-induced IFN- } \gamma \text { increased the VCAM-1 expression on tumor vasculature to facilitate } T \text { cell } \\
\text { infiltration. }\end{array}$ & Lugade et al. (22), \\
\hline Multiple models & $1 \times 6 \mathrm{~Gy}$ & $\begin{array}{l}\text { Liver-directed RT eliminated immunosuppressive hepatic macrophages and increased } \mathrm{T} \text { cell function } \\
\text { in liver metastatic models. }\end{array}$ & Yu et al. (23), \\
\hline Lung adenocarcinoma & $2 \times 1 G y$ & RT induced M1 macrophage polarization and enhanced immune cell infiltration. & $\begin{array}{l}\text { Barsoumian et al. } \\
(24) \text {, }\end{array}$ \\
\hline Multiple models & $2 \times 12.5$ Gy & RT downregulated the expression of VEGF to reduce the recruitment of MDSC into tumors. & Lan et al. (25), \\
\hline Prostate cancer & $2 \times 10 G y$ & RT induced CXCL9 expression, leading to increased CD8 ${ }^{+} \mathrm{T}$ cell infiltration. & Keam et al. (26), \\
\hline \multicolumn{4}{|c|}{ Preclinical evidence of RT in combination with CAR-T cells } \\
\hline Glioblastoma & $1 \times 5 G y$ & RT facilitated vasculature normalization to promote CAR-T cell extravasation in the TME. & $\begin{array}{l}\text { Murty et al. } 2020 \\
(27)\end{array}$ \\
\hline Pancreatic cancer & $1 \times 2 \mathrm{~Gy}$ & RT sensitized antigen-negative tumor cells to TRAIL-dependent killing mediated by CAR-T cells. & $\begin{array}{l}\text { DeSelm et al. } 2018 \\
(28)\end{array}$ \\
\hline Glioblastoma & $1 \times 4 G y$ & RT boosted CAR-T cell activity (IFN- $\gamma$ production) and upregulated CAR-targeted stress ligand. & $\begin{array}{l}\text { Weiss et al. } 2018 \\
\text { (29) }\end{array}$ \\
\hline
\end{tabular}

Diffuse large B-cell $20 \times 2$ Gy RT was related to CAR-T cell expansion and therapeutic durability of CAR-T cell therapy.

NCT03196830 (30) lymphoma

Multiple Myeloma $\quad 5 \times 4 G y$

The synergistic abscopal effect induced by localized RT and CAR-T cells.

NCT03070327 (31) 


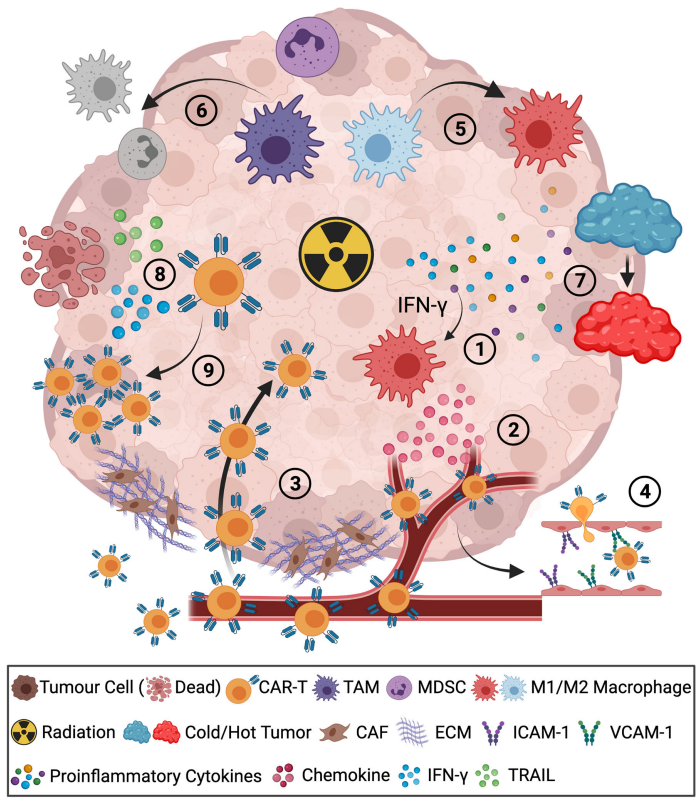

FIGURE 1 | Radiotherapy improves the outcomes of CAR-T cells in combination therapy. (1)Radiation-induced IFN- $\gamma$ promotes chemokine secretion of CXCL9/10/11, (2) leading to effective CAR-T cell homing to the tumor bed. (3Diminished tumor barriers of cancer-associated fibroblasts (CAF) and extracellular matrix (ECM) promote CAR-T cell infiltration. (4Radiationinduced expression of ICAM-1NCAM-1 on the endothelium of tumor vasculature facilitated CAR-T cell infiltration. (5RT polarized M2 macrophages to M1 macrophages in the TME. (6Reduction of TAM and MDSC by RT. (7)Radiation-induced increased expression of proinflammatory cytokines altered the TME from immunosuppressive "cold" to immune-inflamed "hot". (8Radiation enhanced infiltrated CAR-T cell function with increased expression of TRAIL, IFN- $\gamma$ and (9augmented expansion of CAR-T cells. The figure is created with BioRender.com.

(CAFs), epithelium, endothelium, and extracellular matrix (ECM). Together these elements form a micro-environment that inhibits the anti-tumor immune response (33). CAFs are a heterogeneous cell population commonly present in most tumor stroma. CAFmediated aberrant high-density ECM contributes to the exclusion of effector T cells by acting as barriers to immune cell infiltration (34). In addition, CAFs also exhibit pro-tumorigenic capacity by inhibiting effector T cells, polarizing macrophages towards an M2 phenotype, recruiting suppressor cells, and remodeling the ECM (35). Few studies have explored the impact of radiation on CAFs; however, it was reported that RT could alter the pro-tumorigenic status of the tumor stroma (20) and potentially increase CAR-T cell infiltration into the tumor (Figure 1. Step (3).

Tumor-associated hypoxia and dysregulated vasculature are further barriers to $\mathrm{T}$ cell access into tumor stroma. Immunosuppressive tumors, such as prostate cancer, present with a hypoxic environment that excludes the $\mathrm{T}$ cells from infiltration. These hypoxic zones in the TME also recruit and harbor suppressive cells such as MDSC (36). As one of the major influencers in the TME, tumor-associated vasculature also contributes to maintaining an immunosuppressive TME. Proangiogenic factors, such as vascular endothelial growth factor A
(VEGF-A), can reduce $\mathrm{T}$ cell infiltration by disrupting their access to the tumor bed and also inhibit adhesion molecules on endothelium for immune cell extravasation, such as intercellular adhesion molecule (ICAM)-1 and vascular cell adhesion protein (VCAM)-1 (37). RT contributes to the improved normalization of tumor vasculature in the TME. In prostate cancer, fractionated RT altered the function of tumor vasculature to improve tumor reoxygenation (19). Real-time imaging analysis in a glioblastoma model revealed that RT also promoted CAR-T cell extravasation and local expansion leading to a synergistic benefit of the combination treatment (27). In addition, radiation was shown to induce increased expression of the integrins ICAM-1 and VCAM-1 on the endothelium of the vasculature in the TME $(21,22)$, these adhesion molecules are critical for transendothelial migration of CAR-T cells (Figure 1. Step (4).

The migratory activity of CAR-T cells is largely influenced by the CXCR3/CXCL9-11 chemokine receptor-chemokine axis (38). These $\mathrm{T}$ cell recruiting chemokines are produced by M1-like immune-stimulatory macrophages in response to the proinflammatory cytokine IFN- $\gamma(39,40)$. In addition, $\mathrm{CD}^{+} \mathrm{T}$ cell infiltration is also controlled by the CCR5/CCL5 axis (40). However, immunosuppressive tumors lack the pro-inflammatory environment and immune-stimulatory cells to produce the T cell recruiting chemokines. Some tumors also secrete chemokines that recruit suppressive cells, such as regulatory T cell (Treg)-recruiting CCL17/22 and myeloid-derived suppressor cell (MDSC)-recruiting CCL2 (41). As a result, the immunosuppressive tumors present a mismatched chemokine signature for T cell recruitment, leading to limited effector T cell homing and tumor infiltration (42). Radiation-induced inflammation in the TME can promote the recruitment of effector $\mathrm{T}$ cells by triggering macrophages, in an IFN- $\gamma$ dependent manner, to produce increased levels of the CXCR3-reactive T cell chemoattractants CXCL9, CXCL10, and CXCL11 (17, 26) (Figure 1. Steps (12)). Radiation-induced activation of stimulator of interferon genes (STING) pathway was also shown to increase expression of CXCL10 in a mouse mammary carcinoma model refractory to immune checkpoint inhibitors (18).

\section{Immunosuppression in the TME}

The TME comprises a complex network of tumor cells and the tumor stroma made up of endothelial cells, fibroblasts, extracellular matrix, and immune cells (43). Despite sufficient trafficking and expansion of CAR-T cells in TME, suppressor immune cell subsets and soluble mediators can render CAR-T cells exhausted and dysfunctional (44).

Tregs are key contributors to tumor-mediated immune suppression (45). In patients with recurrent glioblastoma, infiltration of Tregs in the TME dampened immune activity and promoted acquired resistance to CAR-T cell therapy (46). Other immunosuppressive subsets that have been shown to impact CAR-T cell function are MDSC and tumor-associated macrophages (TAM) $(47,48)$. MDSCs can generate a suppressive milieu of cytokines and metabolites such as IL-10, TGF- $\beta$, IL-1 receptor antagonist, nitric oxide, and arginase 1 to hinder the tumoricidal immune response (49-52). Neutralizing MDSCs by immunostimulatory agents, such as all-trans retinoic acid, preserved CAR-T cell proliferation and cytotoxic function, and 
resulted in reduced tumor burden in CAR-T treated mice in an osteosarcoma model (53). Similarly, TAM can be co-opted by tumor cells and polarized to an anti-inflammatory M2-like phenotype capable of hindering $\mathrm{T}$ cell responses by the production of inhibitory mediators (i.e., TGF- $\beta$, indoleamine 2,3-dioxygenase IDO) and expression of PD-L1 $(54,55)$. Direct depletion of TAM has proven ineffective in promoting ACT, however, re-wiring of TAM to a pro-inflammatory phenotype by anti-CD40 agonist or blocking AIM2 inflammasome can improve the performance of immunotherapies including CART cells $(56,57)$.

Cytokines and metabolic factors can also contribute to tumor progression and the loss of immune surveillance. The accumulation of lactate and adenosine, by-products of abnormal cellular metabolism in the TME, favors the infiltration and expansion of suppressive TAM and MDSC and dampens the activity of T cells (58-61). Enrichment of the inhibitory cytokine TGF- $\beta$ has also been documented in many cancers and exerts profound immunomodulatory properties to attenuate the cytotoxic potential of $\mathrm{T}$ cells and accelerate $\mathrm{T}$ cell dysfunction $(62,63)$. TGF- $\beta$ can also polarize myeloid cells and B cells towards an immunosuppressive phenotype $(64,65)$. As such, TGF- $\beta$ co-opts various immunosuppressive cells to indirectly counteract immune activation in the TME. Neutralizing the TGF- $\beta$ signal in the TME has been shown to unleash potent $\mathrm{T}$ cell responses, thereby rendering tumors susceptible to immunotherapy, including CAR-T cell treatment $(66,67)$.

Taken together, depleting Tregs and MDSC, reprogramming the TAM, and blocking the associated soluble mediators can be crucial to rescuing anti-cancer immune activity. In this regard, RT has been broadly investigated for its TME altering capacity $(16,32)$. This rationale is further supported by the notion that irradiation can alter the phenotype of immunosuppressive cells in the TME (Figure 1. Step (5). RT has been shown to enrich the TME for M1-like macrophages and reduce the frequency of immunosuppressive M2-like macrophages and MDSC $(23,24,68,69)$ (Figure 1. Step (6). Reduction of MDSC in the peripheral blood of patients post conventionally fractionated RT $(<2$ Gy/fraction) has also been reported (70). Similarly, hypofractionated RT ( $>2$ Gy/fraction), has also been shown to reduce the influx of MDSC in TME by downregulating the expression of VEGF (25). Taken together, RT can boost immune activation by altering the immunosuppression status of the TME to enhance CAR-T cell efficacy.

Aside from its direct ability to debulk tumors, RT can also engage host immune defenses by causing immunogenic cell death (ICD) (71). ICD is associated with the release of danger-associated molecular patterns (DAMP) and increased expression of neoantigens that can help facilitate the recruitment and activation of dendritic cells and subsequent priming of $\mathrm{T}$ cell responses with an expanded TCR repertoire $(72,73)$. Radiation-induced activation of the STING pathway induces expression of Type I IFNs and TNF, leading to an inflammatory microenvironment, which facilitates $\mathrm{T}$ cell activity $(22,74)$ (Figure 1. Step (7)). Of note, the STING response induced by a single fraction of high-dose radiation is distinct from that when the total dose is fractionated into a series of smaller doses. Demaria and colleagues demonstrated that fractionated radiation schedules of less than $8 \mathrm{~Gy} /$ fraction activated the STING pathway and release of Type I IFN, permitting the induction of abscopal response when delivered in combination with ICB therapy. In contrast, a single fraction of 20 Gy RT increased the expression of TREX1 within tumor cells, preventing STING activation and its ability to augment the systemic anti-tumor activity of ICB therapy (18).

\section{The Effect of RT on CAR-T Cell Function}

In addition to the effect of RT on the TME and T cell trafficking, radiation can also promote CAR-T cell function. Radiation can induce tumor cell stress ligands and it is an alternate mechanism through which RT may increase tumor-cell susceptibility to CAR-T cell-mediated killing (Figure 1. Step (8). DeSelm et al. showed that a single fraction of 2 Gy could augment TRAILmediated cytolysis by anti-sialyl Lewis-A CAR-T cells, leading to attenuated tumor growth in mice bearing heterogeneous pancreatic tumors (28). A similar effect was also observed when radiation enhanced the IFN- $\gamma$ production of CAR-T cells in a glioblastoma mouse model (29). In addition, CAR-T cell expansion was correlated with RT in a patient with relapsed diffuse large B cell lymphoma (Figure 1. Step (9). The CAR-T cell transgene copies dropped initially post-infusion but increased dramatically after RT and persisted for more than 120 days, leading to a complete remission post combination treatment (30).

Radiation may also induce the expression of stress ligands that can be targeted by CAR-T cells. NKG2D CAR-T cells combined with local intracranial RT significantly reduced tumor burden and prolonged survival, which can be attributed to the upregulation of NKG2DL, such as RAE-1 and MULT-1 post-irradiation (29).

In addition to the local effects of RT, induction of systemic antitumor immune responses that control tumor growth outside the irradiation volume (known as the abscopal effect), was also reported (75). In a case study of a BCMA CAR-T cell clinical trial, combination with RT showed complete radiographic resolution including the innumerable sites outside the radiation site with no relapse in 9 months post-treatment (31).

More evidence is emerging that certain dose/fractions of RT can, directly and indirectly, affect the CAR-T efficacy against tumor cells, although further detailed mechanisms to explain the benefits of RT on CAR-T cells are still not clear and should be investigated further.

\section{CHALLENGES FOR THE COMBINATION THERAPY OF RT AND CAR-T CELLS}

Although RT and CAR-T therapy have shown therapeutic efficacy in treating some tumors, further consideration is needed when designing the combination therapy to gain the maximum clinical benefit.

For many cancer patients, RT is given post CAR-T cell infusion so the adoptive transferred cells are potentially vulnerable to radiation-induced induce apoptosis (76), however, in vivo data relating to this point remains scarce. Notably, antigen-experienced $\mathrm{T}$ cells, such as memory $\mathrm{CD} 8^{+} \mathrm{T}$ 
cells and tissue-resident memory $\mathrm{T}$ cells have been reported to be more resistant to radiation-induced apoptosis compared to naïve T cells $(77,78)$. Thus, the ex vivo culturing processes necessary to generate CAR T cells may aid in strengthening their resilience to direct exposure to external beam RT. In a clinical trial, low dose RT (2 Gy/fraction) was found to induce in vivo expansion of CAR-T cells (30). Based on our current knowledge of the immunological effects of RT we would expect that low dose RT $(<2-4 \mathrm{~Gy})$ to be a better complement to CAR-T therapy. Lowdose RT is likely to be less impactful on the viability of the immune compartment and has reported positive impacts on TAM and the vasculature as discussed above.

Besides reprogramming the TAM and MDSC in the TME to a proinflammatory phenotype, RT can also induce the wound healing response and the induction of highly suppressive Treg responses (79). Interestingly, the rate and amplitude of accumulation of Tregs within irradiated tumors were dictated by dose per fraction rather than total dose. In this study, a single fraction of 20Gy generated a more aggressive Treg response compared to a fractionated dose of $9 \times 4 \mathrm{~Gy}$, despite sharing the same biological effector dose of 45Gy (79). Several preclinical studies have demonstrated that the targeted depletion of Tregs is required to induce a durable response to RT and support the anti-cancer actions of immune checkpoint blockade therapy (80, 81). Thus, a more precise dose/fraction should be considered, and additional Treg-targeted approaches may be needed to overcome potential immune suppression and acquired resistance. In this regard, other combination treatment strategies could be considered, such as chemotherapy and monoclonal antibodies. Docetaxel was reported to specifically deplete activated Tregs with more IFN- $\gamma$ and less TGF- $\beta$, but not resting Tregs in non-small cell lung cancer (82). In pancreatic ductal adenocarcinoma, low-dose gemcitabine also induced Treg depletion (83). Another approach is to use the monoclonal antibodies (mAbs) targeting the key molecules on Treg cells, such as CTLA-4 (Cytotoxic T lymphocyte-associated antigen-4), CD73, and TIGIT (T cell immunoreceptor with Ig and ITIM domains). Some of these mAbs have been approved for treating cancers, such as Ipilimumab (anti-CTLA-4 mAb), and others are being investigated in clinical trials as reviewed elsewhere (84-86). Similarly, upregulation of inhibitory signaling molecules, such as PD-L1, have been observed on tumor cells post-radiation (87-89). Thus, adding immune checkpoint blockade into the combination therapy may resolve the negative effects of RT and promote the efficacy of CAR-T cells, although the safety and synergistic benefit remain to be evaluated in the clinic.

ATP released from irradiated tumor cells can be converted to adenosine by the ectoenzymes CD39 and CD73, which is another potential barrier for CAR-T cell function (90). Elevated adenosine impedes the anti-tumor response of effector $\mathrm{T}$ cells through their surface A2a adenosine receptors (A2aRs) (91-93). Blocking adenosine signaling has been shown to elicit a more potent T-cell response in combination therapy $(94,95)$. Besides therapeutic inhibitors, this strategy can also be achieved by directly modifying the CAR-T cells. The modification includes depleting the A2aRs in CAR-T cells by CRISPR-Cas9 editing and engineering CAR-T cells to carry antagonist nanoparticles. Both approaches showed increased efficacy with radiation in CD73/ CD39 induced adenosine-enriched tumors $(96,97)$, but not in tumors with weak CD73/CD39 expression, such as melanoma (98). Therefore, for radiation-induced adenosine-rich tumors, inhibitors of the adenosine pathway or the engineering of CAR-T cells to resist adenosine-induced suppression may prove beneficial in the context of RT.

Radiation-induced enrichment of TGF- $\beta$ in the TME is another critical barrier to the effective partnership of RT and CAR-T cells $(26,79)$. The wound healing process and DNA repair programs post-radiation treatment trigger TGF- $\beta$ signaling in the TME, resulting in epithelial-mesenchymal transition, tissue fibrosis, and the induction of a broad spectrum of immunosuppressive effects on infiltrating immune cells including CAR-T cells $(99,100)$. To overcome this barrier, CAR-T cells can be modified to become resistant to TGF- $\beta$ mediated immunosuppression. For example, Kloss et al. engineered a dominant-negative TGF- $\beta$ receptor (dnTGF- $\beta$ RII) capable of binding TGF- $\beta$ without directly triggering a T-cell inhibitory signaling event. This approach proved effective in promoting superior anti-tumor efficacy compared to the parental CAR-T cells in a metastatic prostate cancer model (101). The TGF- $\beta$ on CAR-T cells can also be blocked by knocking out the endogenous TGF- $\beta$ type II receptor (102). However, given the homeostatic function of TGF- $\beta$ signaling in lymphoid tissues, constitutive TGF- $\beta$ blockade may result in offtarget toxicity. Indeed, following treatment with dnTGFßRIIPSMA-CAR-T cells, a subset of patients developed severe cytokine release syndrome and immune effector cell-associated neurotoxicity syndrome (ICANS) (103). Based on these findings, efforts are ongoing to refine this approach. Developing a CAR construct to selectively capture and neutralize TGF- $\beta$ only within the TME may indeed prove to be efficacious and safe.

\section{CONCLUSION}

Combination treatment of RT and CAR-T cells has significant therapeutic potential. Although it is a promising option for patients with immunosuppressive tumors, further considerations on dose/ fraction, treatment schedule, immune context, and tumor type should be considered when designing the treatment, and more mechanistic studies are still needed to understand how these therapies will best work in combination. Our increased understanding of the immunomodulatory effects of RT together with the incredible advances being made in the CAR-T cell field, especially with promising molecular engineering of novel CAR constructs, will facilitate the successful implementation of this combination strategy in the clinic.

\section{AUTHOR CONTRIBUTIONS}

Writing-original draft preparation: VQ, NH, and JZ. Writingreview and editing: NH, CD'S, PN, and JZ. Supervision: PN. All authors contributed to the article and approved the submitted version. 


\section{REFERENCES}

1. Moeller M, Haynes NM, Trapani JA, Teng MW, Jackson JT, Tanner JE, et al. A Functional Role for CD28 Costimulation in Tumor Recognition by SingleChain Receptor-Modified T Cells. Cancer Gene Ther (2004) 11(5):371-9. doi: $10.1038 /$ sj.cgt.7700710

2. Park JH, Riviere I, Gonen M, Wang X, Senechal B, Curran KJ, et al. LongTerm Follow-Up of CD19 CAR Therapy in Acute Lymphoblastic Leukemia. N Engl J Med (2018) 378(5):449-59. doi: 10.1056/NEJMoa1709919

3. Rodriguez-Garcia A, Palazon A, Noguera-Ortega E, Powell DJJr., Guedan S. CAR-T Cells Hit the Tumor Microenvironment: Strategies to Overcome Tumor Escape. Front Immunol (2020) 11:1109. doi: 10.3389/ fimmu.2020.01109

4. Galon J, Bruni D. Approaches to Treat Immune Hot, Altered and Cold Tumours With Combination Immunotherapies. Nat Rev Drug Discov (2019) 18(3):197-218. doi: 10.1038/s41573-018-0007-y

5. Ayers M, Lunceford J, Nebozhyn M, Murphy E, Loboda A, Kaufman DR, et al. IFN-Gamma-Related mRNA Profile Predicts Clinical Response to PD1 Blockade. J Clin Invest (2017) 127(8):2930-40. doi: 10.1172/JCI91190

6. Schadendorf D, Hodi FS, Robert C, Weber JS, Margolin K, Hamid O, et al. Pooled Analysis of Long-Term Survival Data From Phase II and Phase III Trials of Ipilimumab in Unresectable or Metastatic Melanoma. J Clin Oncol (2015) 33(17):1889-94. doi: 10.1200/JCO.2014.56.2736

7. Tumeh PC, Harview CL, Yearley JH, Shintaku IP, Taylor EJ, Robert L, et al. PD-1 Blockade Induces Responses by Inhibiting Adaptive Immune Resistance. Nature (2014) 515(7528):568-71. doi: 10.1038/nature13954

8. Ma V, Griffith K, Waninger J, Daignault-Newton S, Fecher L, Alva A, et al. 241 Clinical Outcomes of Metastatic Melanoma Patients With Liver Metastases Treated With Anti-PD-1 Monotherapy Versus Combination Ipilimumab/Nivolumab. J Immuno Therapy Cancer (2020) 8:A143-A4. doi: 10.1136/jitc-2020-SITC2020.0241

9. Pelster MS, Gruschkus SK, Bassett R, Gombos DS, Shephard M, Posada L, et al. Nivolumab and Ipilimumab in Metastatic Uveal Melanoma: Results From a Single-Arm Phase II Study. J Clin Oncol (2021) 39(6):599-607. doi: 10.1200/JCO.20.00605

10. Strasner A, Karin M. Immune Infiltration and Prostate Cancer. Front Oncol (2015) 5:128. doi: 10.3389/fonc.2015.00128

11. Martinez-Bosch N, Vinaixa J, Navarro P. Immune Evasion in Pancreatic Cancer: From Mechanisms to Therapy. Cancers (Basel) (2018) 10(1):6. doi: 10.3390/cancers 10010006

12. Barton MB, Jacob S, Shafiq J, Wong K, Thompson SR, Hanna TP, et al. Estimating the Demand for Radiotherapy From the Evidence: A Review of Changes From 2003 to 2012. Radiother Oncol (2014) 112(1):140-4. doi: 10.1016/j.radonc.2014.03.024

13. Hua L, Wang Z, Zhao L, Mao H, Wang G, Zhang K, et al. HypoxiaResponsive Lipid-Poly-(Hypoxic Radiosensitized Polyprodrug) Nanoparticles for Glioma Chemo- and Radiotherapy. Theranostics (2018) 8(18):5088-105. doi: 10.7150/thno.26225

14. Grapin M, Richard C, Limagne E, Boidot R, Morgand V, Bertaut A, et al. Optimized Fractionated Radiotherapy With Anti-PD-L1 and Anti-TIGIT: A Promising New Combination. J Immunother Cancer (2019) 7(1):160. doi: 10.1186/s40425-019-0634-9

15. Morisada M, Clavijo PE, Moore E, Sun L, Chamberlin M, Van Waes C, et al. PD1 Blockade Reverses Adaptive Immune Resistance Induced by High-Dose Hypofractionated But Not Low-Dose Daily Fractionated Radiation. Oncoimmunology (2018) 7(3):e1395996. doi: 10.1080/2162402X.2017.1395996

16. McLaughlin M, Patin EC, Pedersen M, Wilkins A, Dillon MT, Melcher AA, et al. Inflammatory Microenvironment Remodelling by Tumour Cells After Radiotherapy. Nat Rev Cancer (2020) 20(4):203-17. doi: 10.1038/s41568020-0246-1

17. Lim JY, Gerber SA, Murphy SP, Lord EM. Type I Interferons Induced by Radiation Therapy Mediate Recruitment and Effector Function of CD8(+) T Cells. Cancer Immunol Immunother (2014) 63(3):259-71. doi: 10.1007/ s00262-013-1506-7

18. Vanpouille-Box C, Alard A, Aryankalayil MJ, Sarfraz Y, Diamond JM, Schneider RJ, et al. DNA Exonuclease Trex1 Regulates RadiotherapyInduced Tumour Immunogenicity. Nat Commun (2017) 8:15618. doi: $10.1038 /$ ncomms15618
19. Potiron VA, Abderrahmani R, Clement-Colmou K, Marionneau-Lambot $S$, Oullier T, Paris F, et al. Improved Functionality of the Vasculature During Conventionally Fractionated Radiation Therapy of Prostate Cancer. PloS One (2013) 8(12):e84076. doi: 10.1371/journal.pone.0084076

20. Grinde MT, Vik J, Camilio KA, Martinez-Zubiaurre I, Hellevik T. Ionizing Radiation Abrogates the Pro-Tumorigenic Capacity of Cancer-Associated Fibroblasts Co-Implanted in Xenografts. Sci Rep (2017) 7:46714. doi: $10.1038 /$ srep 46714

21. Zhao Y, Zhang T, Wang Y, Lu D, Du J, Feng X, et al. ICAM-1 Orchestrates the Abscopal Effect of Tumor Radiotherapy. Proc Natl Acad Sci USA (2021) 118(14):e2010333118. doi: 10.1073/pnas.2010333118

22. Lugade AA, Sorensen EW, Gerber SA, Moran JP, Frelinger JG, Lord EM. Radiation-Induced IFN-Gamma Production Within the Tumor Microenvironment Influences Antitumor Immunity. J Immunol (2008) 180(5):3132-9. doi: 10.4049/jimmunol.180.5.3132

23. Yu J, Green MD, Li S, Sun Y, Journey SN, Choi JE, et al. Liver Metastasis Restrains Immunotherapy Efficacy via Macrophage-Mediated T Cell Elimination. Nat Med (2021) 27(1):152-64. doi: 10.1038/s41591-020-1131-x

24. Barsoumian HB, Ramapriyan R, Younes AI, Caetano MS, Menon H, Comeaux NI, et al. Low-Dose Radiation Treatment Enhances Systemic Antitumor Immune Responses by Overcoming the Inhibitory Stroma. J Immunother Cancer (2020) 8(2):e000537. doi: 10.1136/jitc-2020-000537

25. Lan J, Li R, Yin LM, Deng L, Gui J, Chen BQ, et al. Targeting MyeloidDerived Suppressor Cells and Programmed Death Ligand 1 Confers Therapeutic Advantage of Ablative Hypofractionated Radiation Therapy Compared With Conventional Fractionated Radiation Therapy. Int J Radiat Oncol Biol Phys (2018) 101(1):74-87. doi: 10.1016/j.ijrobp.2018.01.071

26. Keam SP, Halse H, Nguyen T, Wang M, Van Kooten Losio N, Mitchell C, et al. High Dose-Rate Brachytherapy of Localized Prostate Cancer Converts Tumors From Cold to Hot. J Immunother Cancer (2020) 8(1):e000792. doi: 10.1136/jitc-2020-000792

27. Murty S, Haile ST, Beinat C, Aalipour A, Alam IS, Murty T, et al. Intravital Imaging Reveals Synergistic Effect of CAR T-Cells and Radiation Therapy in a Preclinical Immunocompetent Glioblastoma Model. Oncoimmunology (2020) 9(1):1757360. doi: 10.1080/2162402X.2020.1757360

28. DeSelm C, Palomba ML, Yahalom J, Hamieh M, Eyquem J, Rajasekhar VK, et al. Low-Dose Radiation Conditioning Enables CAR T Cells to Mitigate Antigen Escape. Mol Ther (2018) 26(11):2542-52. doi: 10.1016/j.ymthe.2018.09.008

29. Weiss T, Weller M, Guckenberger M, Sentman CL, Roth P. NKG2D-Based CAR T Cells and Radiotherapy Exert Synergistic Efficacy in Glioblastoma. Cancer Res (2018) 78(4):1031-43. doi: 10.1158/0008-5472.CAN-17-1788

30. Qu C, Ping N, Kang L, Liu H, Qin S, Wu Q, et al. Radiation Priming Chimeric Antigen Receptor T-Cell Therapy in Relapsed/Refractory Diffuse Large B-Cell Lymphoma With High Tumor Burden. J Immunother (2020) 43(1):32-7. doi: 10.1097/CJI.0000000000000284

31. Smith EL, Mailankody S, Staehr M, Wang X, Senechal B, Purdon TJ, et al. BCMA-Targeted CAR T-Cell Therapy Plus Radiotherapy for the Treatment of Refractory Myeloma Reveals Potential Synergy. Cancer Immunol Res (2019) 7(7):1047-53. doi: 10.1158/2326-6066.CIR-18-0551

32. Barker HE, Paget JT, Khan AA, Harrington KJ. The Tumour Microenvironment After Radiotherapy: Mechanisms of Resistance and Recurrence. Nat Rev Cancer (2015) 15(7):409-25. doi: 10.1038/nrc3958

33. Valkenburg KC, de Groot AE, Pienta KJ. Targeting the Tumour Stroma to Improve Cancer Therapy. Nat Rev Clin Oncol (2018) 15(6):366-81. doi: 10.1038/s41571-018-0007-1

34. Henke E, Nandigama R, Ergun S. Extracellular Matrix in the Tumor Microenvironment and Its Impact on Cancer Therapy. Front Mol Biosci (2019) 6:160. doi: 10.3389/fmolb.2019.00160

35. Monteran L, Erez N. The Dark Side of Fibroblasts: Cancer-Associated Fibroblasts as Mediators of Immunosuppression in the Tumor Microenvironment. Front Immunol (2019) 10:1835. doi: 10.3389/fimmu.2019.01835

36. Jayaprakash P, Ai M, Liu A, Budhani P, Bartkowiak T, Sheng J, et al. Targeted Hypoxia Reduction Restores T Cell Infiltration and Sensitizes Prostate Cancer to Immunotherapy. J Clin Invest (2018) 128(11):5137-49. doi: 10.1172/JCI96268

37. Schaaf MB, Garg AD, Agostinis P. Defining the Role of the Tumor Vasculature in Antitumor Immunity and Immunotherapy. Cell Death Dis (2018) 9(2):115. doi: 10.1038/s41419-017-0061-0 
38. Spranger S, Dai D, Horton B, Gajewski TF. Tumor-Residing Batf3 Dendritic Cells Are Required for Effector T Cell Trafficking and Adoptive T Cell Therapy. Cancer Cell (2017) 31(5):711-23 e4. doi: 10.1016/j.ccell.2017. 04.003

39. House IG, Savas P, Lai J, Chen AXY, Oliver AJ, Teo ZL, et al. MacrophageDerived CXCL9 and CXCL10 Are Required for Antitumor Immune Responses Following Immune Checkpoint Blockade. Clin Cancer Res (2020) 26(2):487-504. doi: 10.1158/1078-0432.CCR-19-1868

40. Dangaj D, Bruand M, Grimm AJ, Ronet C, Barras D, Duttagupta PA, et al. Cooperation Between Constitutive and Inducible Chemokines Enables $\mathrm{T}$ Cell Engraftment and Immune Attack in Solid Tumors. Cancer Cell (2019) 35(6):885-900 e10. doi: 10.1016/j.ccell.2019.05.004

41. Kohli K, Pillarisetty VG, Kim TS. Key Chemokines Direct Migration of Immune Cells in Solid Tumors. Cancer Gene Ther (2021). doi: 10.1038/ s41417-021-00303-x

42. Sackstein R, Schatton T, Barthel SR. T-Lymphocyte Homing: An Underappreciated Yet Critical Hurdle for Successful Cancer Immunotherapy. Lab Invest (2017) 97(6):669-97. doi: 10.1038/labinvest.2017.25

43. Garner H, de Visser KE. Immune Crosstalk in Cancer Progression and Metastatic Spread: A Complex Conversation. Nat Rev Immunol (2020) 20 (8):483-97. doi: 10.1038/s41577-019-0271-z

44. Moon EK, Wang LC, Dolfi DV, Wilson CB, Ranganathan R, Sun J, et al. Multifactorial T-Cell Hypofunction That Is Reversible can Limit the Efficacy of Chimeric Antigen Receptor-Transduced Human T Cells in Solid Tumors. Clin Cancer Res (2014) 20(16):4262-73. doi: 10.1158/1078-0432.CCR-13-2627

45. Paluskievicz CM, Cao X, Abdi R, Zheng P, Liu Y, Bromberg IS. T Regulatory Cells and Priming the Suppressive Tumor Microenvironment. Front Immunol (2019) 10:2453. doi: 10.3389/fimmu.2019.02453

46. O'Rourke DM, Nasrallah MP, Desai A, Melenhorst JJ, Mansfield K, Morrissette JJD, et al. A Single Dose of Peripherally Infused EGFRvIIIDirected CAR T Cells Mediates Antigen Loss and Induces Adaptive Resistance in Patients With Recurrent Glioblastoma. Sci Transl Med (2017) 9(399):eaaa0984. doi: 10.1126/scitranslmed.aaa0984

47. Li K, Shi H, Zhang B, Ou X, Ma Q, Chen Y, et al. Myeloid-Derived Suppressor Cells as Immunosuppressive Regulators and Therapeutic Targets in Cancer. Signal Transduct Target Ther (2021) 6(1):362. doi: 10.1038/s41392-021-00670-9

48. DeNardo DG, Ruffell B. Macrophages as Regulators of Tumour Immunity and Immunotherapy. Nat Rev Immunol (2019) 19(6):369-82. doi: 10.1038/ s41577-019-0127-6

49. Steggerda SM, Bennett MK, Chen J, Emberley E, Huang T, Janes JR, et al. Inhibition of Arginase by CB-1158 Blocks Myeloid Cell-Mediated Immune Suppression in the Tumor Microenvironment. J Immunother Cancer (2017) 5(1):101. doi: 10.1186/s40425-017-0308-4

50. Feng S, Cheng X, Zhang L, Lu X, Chaudhary S, Teng R, et al. MyeloidDerived Suppressor Cells Inhibit $\mathrm{T}$ Cell Activation Through Nitrating LCK in Mouse Cancers. Proc Natl Acad Sci USA (2018) 115(40):10094-9. doi: 10.1073/pnas. 1800695115

51. Lu X, Horner JW, Paul E, Shang X, Troncoso P, Deng P, et al. Effective Combinatorial Immunotherapy for Castration-Resistant Prostate Cancer. Nature (2017) 543(7647):728-32. doi: 10.1038/nature21676

52. Bronte V, Brandau S, Chen SH, Colombo MP, Frey AB, Greten TF, et al. Recommendations for Myeloid-Derived Suppressor Cell Nomenclature and Characterization Standards. Nat Commun (2016) 7:12150. doi: 10.1038/ ncomms 12150

53. Long AH, Highfill SL, Cui Y, Smith JP, Walker AJ, Ramakrishna S, et al. Reduction of MDSCs With All-Trans Retinoic Acid Improves CAR Therapy Efficacy for Sarcomas. Cancer Immunol Res (2016) 4(10):869-80. doi: 10.1158/2326-6066.CIR-15-0230

54. Su S, Zhao J, Xing Y, Zhang X, Liu J, Ouyang Q, et al. Immune Checkpoint Inhibition Overcomes ADCP-Induced Immunosuppression by Macrophages. Cell (2018) 175(2):442-57 e23. doi: 10.1016/j.cell.2018.09.007

55. Lundholm M, Hagglof C, Wikberg ML, Stattin P, Egevad L, Bergh A, et al. Secreted Factors From Colorectal and Prostate Cancer Cells Skew the Immune Response in Opposite Directions. Sci Rep (2015) 5:15651. doi: 10.1038/srep15651

56. Stromnes IM, Burrack AL, Hulbert A, Bonson P, Black C, Brockenbrough JS, et al. Differential Effects of Depleting Versus Programming Tumor-
Associated Macrophages on Engineered T Cells in Pancreatic Ductal Adenocarcinoma. Cancer Immunol Res (2019) 7(6):977-89. doi: 10.1158/ 2326-6066.CIR-18-0448

57. Liu D, Xu X, Dai Y, Zhao X, Bao S, Ma W, et al. Blockade of AIM2 Inflammasome or Alpha1-AR Ameliorates IL-1beta Release and Macrophage-Mediated Immunosuppression Induced by CAR-T Treatment. J Immunother Cancer (2021) 9(1):e001466. doi: 10.1136/jitc2020-001466

58. Yang R, Elsaadi S, Misund K, Abdollahi P, Vandsemb EN, Moen SH, et al. Conversion of ATP to Adenosine by CD39 and CD73 in Multiple Myeloma can be Successfully Targeted Together With Adenosine Receptor A2A Blockade. J Immunother Cancer (2020) 8(1):e000610. doi: 10.1136/jitc2020-000610

59. Ryzhov S, Novitskiy SV, Goldstein AE, Biktasova A, Blackburn MR, Biaggioni I, et al. Adenosinergic Regulation of the Expansion and Immunosuppressive Activity of CD11b+Gr1+ Cells. J Immunol (2011) 187 (11):6120-9. doi: 10.4049/jimmunol.1101225

60. Brand A, Singer K, Koehl GE, Kolitzus M, Schoenhammer G, Thiel A, et al. LDHA-Associated Lactic Acid Production Blunts Tumor Immunosurveillance by T and NK Cells. Cell Metab (2016) 24(5):657-71. doi: 10.1016/j.cmet.2016.08.011

61. Wang H, Franco F, Tsui YC, Xie X, Trefny MP, Zappasodi R, et al. CD36Mediated Metabolic Adaptation Supports Regulatory T Cell Survival and Function in Tumors. Nat Immunol (2020) 21(3):298-308. doi: 10.1038/ s41590-019-0589-5

62. Park BV, Freeman ZT, Ghasemzadeh A, Chattergoon MA, Rutebemberwa A, Steigner J, et al. TGFbeta1-Mediated SMAD3 Enhances PD-1 Expression on Antigen-Specific T Cells in Cancer. Cancer Discov (2016) 6(12):1366-81. doi: 10.1158/2159-8290.CD-15-1347

63. Donkor MK, Sarkar A, Savage PA, Franklin RA, Johnson LK, Jungbluth AA, et al. T Cell Surveillance of Oncogene-Induced Prostate Cancer is Impeded by T Cell-Derived TGF-Beta1 Cytokine. Immunity (2011) 35(1):123-34. doi: 10.1016/j.immuni.2011.04.019

64. Shalapour S, Font-Burgada J, Di Caro G, Zhong Z, Sanchez-Lopez E, Dhar $\mathrm{D}$, et al. Immunosuppressive Plasma Cells Impede T-Cell-Dependent Immunogenic Chemotherapy. Nature (2015) 521(7550):94-8. doi: 10.1038/nature14395

65. Gonzalez-Junca A, Driscoll KE, Pellicciotta I, Du S, Lo CH, Roy R, et al. Autocrine TGFbeta Is a Survival Factor for Monocytes and Drives Immunosuppressive Lineage Commitment. Cancer Immunol Res (2019) 7 (2):306-20. doi: 10.1158/2326-6066.CIR-18-0310

66. Tauriello DVF, Palomo-Ponce S, Stork D, Berenguer-Llergo A, BadiaRamentol J, Iglesias M, et al. TGFbeta Drives Immune Evasion in Genetically Reconstituted Colon Cancer Metastasis. Nature (2018) 554 (7693):538-43. doi: 10.1038/nature25492

67. Stuber T, Monjezi R, Wallstabe L, Kuhnemundt J, Nietzer SL, Dandekar G, et al. Inhibition of TGF-Beta-Receptor Signaling Augments the Antitumor Function of ROR1-Specific CAR T-Cells Against Triple-Negative Breast Cancer. J Immunother Cancer (2020) 8(1):e000676. doi: 10.1136/jitc-2020000676

68. Klug F, Prakash H, Huber PE, Seibel T, Bender N, Halama N, et al. LowDose Irradiation Programs Macrophage Differentiation to an iNOS(+)/M1 Phenotype That Orchestrates Effective T Cell Immunotherapy. Cancer Cell (2013) 24(5):589-602. doi: 10.1016/j.ccr.2013.09.014

69. Prakash H, Klug F, Nadella V, Mazumdar V, Schmitz-Winnenthal H, Umansky L. Low Doses of Gamma Irradiation Potentially Modifies Immunosuppressive Tumor Microenvironment by Retuning TumorAssociated Macrophages: Lesson From Insulinoma. Carcinogenesis (2016) 37(3):301-13. doi: 10.1093/carcin/bgw007

70. Navarro-Martin A, Galiana IL, Berenguer Frances MA, Cacicedo J, Canas Cortes R, Comas Anton S, et al. Preliminary Study of the Effect of Stereotactic Body Radiotherapy (SBRT) on the Immune System in Lung Cancer Patients Unfit for Surgery: Immunophenotyping Analysis. Int J Mol Sci (2018) 19(12):3963. doi: 10.3390/ijms19123963

71. Golden EB, Frances D, Pellicciotta I, Demaria S, Helen Barcellos-Hoff M, Formenti SC. Radiation Fosters Dose-Dependent and ChemotherapyInduced Immunogenic Cell Death. Oncoimmunology (2014) 3:e28518. doi: $10.4161 /$ onci.28518 
72. Apetoh L, Ghiringhelli F, Tesniere A, Obeid M, Ortiz C, Criollo A, et al. TollLike Receptor 4-Dependent Contribution of the Immune System to Anticancer Chemotherapy and Radiotherapy. Nat Med (2007) 13(9):10509. doi: $10.1038 / \mathrm{nm} 1622$

73. Lhuillier C, Rudqvist NP, Yamazaki T, Zhang T, Charpentier M, Galluzzi L, et al. Radiotherapy-Exposed CD8+ and CD4+ Neoantigens Enhance Tumor Control. J Clin Invest (2021) 131(5):e138740. doi: 10.1172/JCI138740

74. Wei S, Egenti MU, Teitz-Tennenbaum S, Zou W, Chang AE. Effects of Tumor Irradiation on Host T-Regulatory Cells and Systemic Immunity in the Context of Adoptive T-Cell Therapy in Mice. J Immunother (2013) 36 (2):124-32. doi: 10.1097/CJI.0b013e31828298e6

75. Ngwa W, Irabor OC, Schoenfeld JD, Hesser J, Demaria S, Formenti SC. Using Immunotherapy to Boost the Abscopal Effect. Nat Rev Cancer (2018) 18(5):313-22. doi: 10.1038/nrc.2018.6

76. Schnarr K, Boreham D, Sathya J, Julian J, Dayes IS. Radiation-Induced Lymphocyte Apoptosis to Predict Radiation Therapy Late Toxicity in Prostate Cancer Patients. Int J Radiat Oncol Biol Phys (2009) 74(5):142430. doi: $10.1016 /$ j.ijrobp.2008.10.039

77. Grayson JM, Harrington LE, Lanier JG, Wherry EJ, Ahmed R. Differential Sensitivity of Naive and Memory CD8+ T Cells to Apoptosis In Vivo. J Immunol (2002) 169(7):3760-70. doi: 10.4049/jimmunol.169.7.3760

78. Arina A, Beckett M, Fernandez C, Zheng W, Pitroda S, Chmura SJ, et al. Tumor-Reprogrammed Resident T Cells Resist Radiation to Control Tumors. Nat Commun (2019) 10(1):3959. doi: 10.1038/s41467-019-11906-2

79. Sia J, Hagekyriakou J, Chindris I, Albarakati H, Leong T, Schlenker R, et al. Regulatory T Cells Shape the Differential Impact of Radiation DoseFractionation Schedules on Host Innate and Adaptive Antitumor Immune Defenses. Int J Radiat Oncol Biol Phys (2021) 111(2):502-14. doi: 10.1016/ j.ijrobp.2021.05.014

80. Oweida A, Hararah MK, Phan A, Binder D, Bhatia S, Lennon S, et al. Resistance to Radiotherapy and PD-L1 Blockade Is Mediated by TIM-3 Upregulation and Regulatory T-Cell Infiltration. Clin Cancer Res (2018) 24 (21):5368-80. doi: 10.1158/1078-0432.CCR-18-1038

81. Oweida AJ, Darragh L, Phan A, Binder D, Bhatia S, Mueller A, et al. STAT3 Modulation of Regulatory T Cells in Response to Radiation Therapy in Head and Neck Cancer. J Natl Cancer Inst (2019) 111(12):1339-49. doi: 10.1093/ jnci/djz036

82. Li JY, Duan XF, Wang LP, Xu YJ, Huang L, Zhang TF, et al. Selective Depletion of Regulatory T Cell Subsets by Docetaxel Treatment in Patients With Nonsmall Cell Lung Cancer. J Immunol Res (2014) 2014:286170. doi: $10.1155 / 2014 / 286170$

83. Shevchenko I, Karakhanova S, Soltek S, Link J, Bayry J, Werner J, et al. LowDose Gemcitabine Depletes Regulatory T Cells and Improves Survival in the Orthotopic Panc02 Model of Pancreatic Cancer. Int J Cancer (2013) 133 (1):98-107. doi: 10.1002/ijc.27990

84. Sobhani N, Tardiel-Cyril DR, Davtyan A, Generali D, Roudi R, Li Y. CTLA-4 in Regulatory T Cells for Cancer Immunotherapy. Cancers (Basel) (2021) 13 (6):1440. doi: $10.3390 /$ cancers 13061440

85. Roh M, Wainwright DA, Wu JD, Wan Y, Zhang B. Targeting CD73 to Augment Cancer Immunotherapy. Curr Opin Pharmacol (2020) 53:66-76. doi: 10.1016/j.coph.2020.07.001

86. Rotte A, Sahasranaman S, Budha N. Targeting TIGIT for Immunotherapy of Cancer: Update on Clinical Development. Biomedicines (2021) 9(9):1277. doi: 10.3390/biomedicines 9091277

87. Sato H, Niimi A, Yasuhara T, Permata TBM, Hagiwara Y, Isono M, et al. DNA Double-Strand Break Repair Pathway Regulates PD-L1 Expression in Cancer Cells. Nat Commun (2017) 8(1):1751. doi: 10.1038/s41467-017-01883-9

88. Dovedi SJ, Adlard AL, Lipowska-Bhalla G, McKenna C, Jones S, Cheadle EJ, et al. Acquired Resistance to Fractionated Radiotherapy Can be Overcome by Concurrent PD-L1 Blockade. Cancer Res (2014) 74(19):5458-68. doi: 10.1158/0008-5472.CAN-14-1258

89. Liu M, Wang X, Li W, Yu X, Flores-Villanueva P, Xu-Monette ZY, et al. Targeting PD-L1 in Non-Small Cell Lung Cancer Using CAR T Cells. Oncogenesis (2020) 9(8):72. doi: 10.1038/s41389-020-00257-z

90. Wirsdorfer F, de Leve S, Cappuccini F, Eldh T, Meyer AV, Gau E, et al. Extracellular Adenosine Production by Ecto-5'-Nucleotidase (CD73) Enhances Radiation-Induced Lung Fibrosis. Cancer Res (2016) 76 (10):3045-56. doi: 10.1158/0008-5472.CAN-15-2310
91. Jin H, Lee JS, Kim DC, Ko YS, Lee GW, Kim HJ. Increased Extracellular Adenosine in Radiotherapy-Resistant Breast Cancer Cells Enhances Tumor Progression Through A2AR-Akt-Beta-Catenin Signaling. Cancers (Basel) (2021) 13(9):2105. doi: 10.3390/cancers13092105

92. Sorrentino C, Hossain F, Rodriguez PC, Sierra RA, Pannuti A, Osborne BA, et al. Adenosine A2A Receptor Stimulation Inhibits TCR-Induced Notch1 Activation in CD8+T-Cells. Front Immunol (2019) 10:162. doi: 10.3389/ fimmu.2019.00162

93. Young A, Ngiow SF, Gao Y, Patch AM, Barkauskas DS, Messaoudene M, et al. A2AR Adenosine Signaling Suppresses Natural Killer Cell Maturation in the Tumor Microenvironment. Cancer Res (2018) 78(4):1003-16. doi: 10.1158/0008-5472.CAN-17-2826

94. Wennerberg E, Spada S, Rudqvist NP, Lhuillier C, Gruber S, Chen Q, et al. CD73 Blockade Promotes Dendritic Cell Infiltration of Irradiated Tumors and Tumor Rejection. Cancer Immunol Res (2020) 8(4):465-78. doi: 10.1158/2326-6066.CIR-19-0449

95. Tsukui H, Horie H, Koinuma K, Ohzawa H, Sakuma Y, Hosoya Y, et al. CD73 Blockade Enhances the Local and Abscopal Effects of Radiotherapy in a Murine Rectal Cancer Model. BMC Cancer (2020) 20(1):411. doi: 10.1186/ s12885-020-06893-3

96. Siriwon N, Kim YJ, Siegler E, Chen X, Rohrs JA, Liu Y, et al. CAR-T Cells Surface-Engineered With Drug-Encapsulated Nanoparticles Can Ameliorate Intratumoral T-Cell Hypofunction. Cancer Immunol Res (2018) 6(7):81224. doi: 10.1158/2326-6066.CIR-17-0502

97. Giuffrida L, Sek K, Henderson MA, Lai J, Chen AXY, Meyran D, et al. CRISPR/Cas9 Mediated Deletion of the Adenosine A2A Receptor Enhances CAR T Cell Efficacy. Nat Commun (2021) 12(1):3236. doi: 10.1038/s41467021-23331-5

98. Mayer A, Haist M, Loquai C, Grabbe S, Rapp M, Roth W, et al. Role of Hypoxia and the Adenosine System in Immune Evasion and Prognosis of Patients With Brain Metastases of Melanoma: A Multiplex Whole Slide Immunofluorescence Study. Cancers (Basel) (2020) 12(12):3753. doi: $10.3390 /$ cancers 12123753

99. Derynck R, Turley SJ, Akhurst RJ. TGFbeta Biology in Cancer Progression and Immunotherapy. Nat Rev Clin Oncol (2021) 18(1):9-34. doi: 10.1038/ s41571-020-0403-1

100. Vanpouille-Box C, Diamond JM, Pilones KA, Zavadil J, Babb JS, Formenti SC, et al. TGFbeta Is a Master Regulator of Radiation Therapy-Induced Antitumor Immunity. Cancer Res (2015) 75(11):2232-42. doi: 10.1158/00085472.CAN-14-3511

101. Kloss CC, Lee J, Zhang A, Chen F, Melenhorst JJ, Lacey SF, et al. DominantNegative TGF-Beta Receptor Enhances PSMA-Targeted Human CAR T Cell Proliferation And Augments Prostate Cancer Eradication. Mol Ther (2018) 26(7):1855-66. doi: 10.1016/j.ymthe.2018.05.003

102. Tang N, Cheng C, Zhang X, Qiao M, Li N, Mu W, et al. TGF-Beta Inhibition via CRISPR Promotes the Long-Term Efficacy of CAR T Cells Against Solid Tumors. JCI Insight (2020) 5(4):e133977. doi: 10.1172/jci.insight.133977

103. Narayan V, Barber-Rotenberg J, Fraietta J, Hwang W-T, Lacey SF, Plesa G, et al. A Phase I Clinical Trial of PSMA-Directed/Tgfß-Insensitive CAR-T Cells in Metastatic Castration-Resistant Prostate Cancer. J Clin Oncol (2021) 39(6_suppl):125-. doi: 10.1200/JCO.2021.39.6_suppl.125

Conflict of Interest: The authors declare that the research was conducted in the absence of any commercial or financial relationships that could be construed as a potential conflict of interest.

Publisher's Note: All claims expressed in this article are solely those of the authors and do not necessarily represent those of their affiliated organizations, or those of the publisher, the editors and the reviewers. Any product that may be evaluated in this article, or claim that may be made by its manufacturer, is not guaranteed or endorsed by the publisher.

Copyright $\odot 2022$ Qin, Haynes, D'Souza, Neeson and Zhu. This is an open-access article distributed under the terms of the Creative Commons Attribution License (CC BY). The use, distribution or reproduction in other forums is permitted, provided the original author(s) and the copyright owner(s) are credited and that the original publication in this journal is cited, in accordance with accepted academic practice. No use, distribution or reproduction is permitted which does not comply with these terms. 